\title{
The Development of Smart Grid and Its Key Technology
}

\author{
Guangyu ZHOU \\ Helongjiang Province Water Conservancy \& Hydropower Investigation, Design and Research Institute, \\ Haerbin, Heilongjiang Province, China
}

\begin{abstract}
This paper discusses the general situation of the development of smart grid home and abroad, analysis the characteristics and advantages of the smart grid, summarizes of the key technologies of smart grid, And the development prospect of smart grid are optimistic prospect. The smart grid is the inevitable direction of development of power industry all over the world. The construction of smart grid in China is in the stage of brook no delay, and great benefit can also be get from it.
\end{abstract}

KEYWORD: Smart Grid; Micro Grid; Electricity Generation, Distributed Power Supply; Advanced Power Electronic Apparatus

\section{INTRODUCE}

"Smart grid" was proposed and begun to study by American Electric Power Research Institute (Electric Power Research Institute, EPRI) in 2001. In 2005 the "smart grid (Smart Grids) European technology forum" was set up in European, that risen "Smart Grids" to the strategic status of research. In 2008, the "smart grid" is defined as the accepted terminology and the title of "The Smart Grid" in the US-China clean energy cooperation organization special meeting and Sino US Green Energy Forum.[1][2]

There are many forms of definition of smart grid since it was proposed internationally. State Grid Electric Power Research Institute of China State Grid Electric Power Research Institute of Chinese defines it as: the physics based on grid (smart grid China is in UHV power network as the backbone grid, strong grid of each voltage grade the coordinated development of the power grid based), new grid would be modern and advanced sensing technology, communication technology, information technology, computer technology, control technology, physical power and the formation of highly integrated. It is to fully meet user's demand for electricity and optimize the allocation of resources, ensure the power supply security, reliability and economy, meet environmental constraints, ensuring the quality of electric energy, adapt to the power market development for the purpose, to realize user reliable, economic, clean, interactive power supply and value-added services.

\section{THE DEVELOPMENT SURVEY OF FOREIGN}

\subsection{Development of American National Smart Grid}

It was started to actively promote the construction of modern power grid in America from Bush government period. The government signed the "energy independence and Security Act" (EISA 2007 ) in 2007. The smart grid is proposed as a chapter in the act of independence. The smart grid American officially became the national strategy.

USA smart grid development focuses on distribution network, is committed to the application of communication technology and intelligent control technology to improve the intelligence of the grid, emphasizes participation and user interaction, by providing real-time price information and abundant control method for the user, to guide the user to change the demand response, the peak and valley filling, so that the load curve tends to be flat, so that the a part of reserve capacity to be used, construction delay generators and transmission lines, and profit from it.

\subsection{European smart grid development}

Platform of smart grid technology in Europe a formal operation in 2005, with 2020 as the target year, development planning and to promote the European grid technology. The development of smart grid access Europe focused on the development of renewable energy and transnational interconnected power grid. 


\subsection{Japan's development of the smart grid}

At present, Japan's Tokyo Electric Power Company's power grid is thought to be the only system in the world close to smart grid. Through the optical fiber communication network, it is gradually realized the real-time measurement and automatic control of $6 \mathrm{kV}$ medium voltage feeder for system wide, began to realize the advanced distribution automation(ADA).

\subsection{Korea smart grid development}

South Korea in 2004 December started the "electric power information engineering", In order to enhance the reliability and security of power system, through asset management to reduce operation and maintenance costs, the demand response increased the efficiency of electricity market, to provide electric power new value-added services. South Korea established a comprehensive smart grid pilot project -- "green power IT" in 2011, vigorously promote the use of IT technology to commercial applications of smart grid.

The development process of smart grid in the world, the general will focus on the development in new energy power generation, distributed generation, information, automation and other fields, it is also consistent with the energy requirements of clean, efficient, reliable and flexible in twenty-first Century.

\section{THE GENERAL SITUATION OF THE DEVELOPMENT OF OUR COUNTRY}

In 2001, the Chinese Academy of Sciences, Professor Lu Qiang put forward the "new-concept of digital power system". In 2005 July, Guangxi Power Grid Corp set up a digital grid research center, relevant research specializing in smart grid, the fast simulation and modeling, system of intelligent early warning technology, optimization scheduling technology, prevention and control-technology, the handling of the accident and accident recovery technology, intelligent data mining technology, scheduling decision visualization, emergency command system and management platform in to carry out a lot of research work. In 2007 October, East Power Grid Corp also officially launched the project feasibility study of smart grid, combined with domestic and foreign advanced electric power enterprises and research institutions research achievements on the smart grid and East China power grid, the current situation and development needs, put forward the development plan and the plan of action for the smart grid construction of East China power grid.

International Conference on UHV transmission technology held in May 2009 on the China State Grid Corp officially announced the "strong smart grid" plan, 10 years will be China's smart grid construction is divided into "planning" pilot project "overall construction" and "leading to improve the" three stages, plan on 2016, in the strong and smart grid in China comprehensively build unified, technology and equipment have reached the international advanced level.

At present, China's construction of smart grid in the power generation side of focus on the construction of large scale renewable energy power generation, focusing on special high-voltage power grid construction in the transmission side, the promotion in the power distribution and power consumption focuses on digital substation and smart meter. "Twelfth Five Year Plan" period, China's electricity load will increase exponentially, the power infrastructure of our country will be in a high speed development period of construction, "the project of power transmission from west to East" will also continue to develop, in order to achieve the optimal allocation of resources of the whole society.

\section{THE KEY TECHNOLOGY OF EVERY LINK OF SMART GRID}

Electricity generation: System, the key technology in the conventional generation sectors including energy complete automated control new conventional power form fast synchronization device, reservoir dispatching control, unit equipment, state monitoring, fault analysis system and the sub synchronous oscillation suppression device etc.. In renewable energy power generation key technologies include new energy power generation monitoring system, scenery complementary power cogeneration intelligent monitoring system, class MW photovoltaic grid connected inverter, intermittent power predictive scheduling, predict scheduling and scenery storage of intelligent control system. In large-scale energy storage key technology including chemical battery energy storage power station, the amount of intelligent dispatching, superconducting energy storagecapacitor device, chemical battery module integration and integrated energy storage power smooth adjustment etc..

Micro grid[3][4][5]: Micro grid that has distributed power with electronic system, with the main flexible connecting or disconnecting. It is connected with main grid normally. When the power grid fault occurs, the main detachment with normal work, maintain all or important load power supply. Micro network using wind energy, solar energy, diesel generators, energy storage and other complementary mode suit one's measures to local conditions, design and construction, the formation of a kind of new energy power generation system of high performance to price ratio, can provide the most suitable is the cheapest power service. The use of 
micro grid technology, not only can solve the remote agricultural and pastoral areas, islands, border posts and other areas without electricity electricity problems. Areas covered in the power grid, can also be used in grid connected mode, maximize there new able energy power generation technology in the economy, energy and environment advantages.

Distributed power supply[6]: In the smart grid interconnection standards improved, making all kinds of power system and the storage system is easier to access, can realize the interconnection in various voltage levels on the. Distributed power unit refers to the power of a few kilowatts to $50 \mathrm{MW}$ small modular, and independent power supply environment compatible. The power from the power sector, power users or the third party of all, in order to satisfy the power system and the user specific requirements. Such as the peak, for remote user or business district and residential power transmission, save investment and improve the reliability of power supply and so on. With the development of technology, the distributed power supply technology more and more mature, and diversification, energy saving, environmental protection direction.

Advanced power electronic apparatus: The use of power electronic equipment can improve and control the quality of electric energy, providing user satisfaction, to meet their specific needs of power. With the flexible AC transmission (flexible AC transmission system, FACTS) technology, high voltage direct current transmission (high voltage DC, HVDC) technology, custom power (custom power) technology and energy conversion technology and the advanced power electronic technology as the representative of the more widely used in power network in our country, it is the important basis and method the construction of a unified smart grid. Strengthen the advanced power electronic technology and the progress of science and technology is an important strategic task, to ensure the long-term development of China power grid

\section{CONCLUSION}

The smart grid is a profound revolution in twentyfirst Century of the power system, the development and construction of it will change the power system operation mode and people's way to grid electricity, the realization of the medium of social resources optimization allocation and rational and efficient use of energy, improve the safety level of the country, and has great social benefit and economic benefit.

\section{REFERENCES}

[1]EPRI. 2003. Power delivery system and electricity markets of the future, Palo Alto CA, USA: EPRI.

[2]European Commission. 2008. European technology platform smart grids: vision ande strategy for Europe's electricit networks of the future. http://ec.europa.eu/research/energy/pdf/smartgrids_en.pdf.

[3]Lu Zongxiang, Wang Caixia 2007. Overview on micro-grid research. Automation of Electric Power System 31(19): 100-107.

[4]Chen shuyong, Song shufang, 2009. Survey on smart grid technology. Power System Technology 33(8): 1-7.

[5]Zhang ling, Wang wei, Sheng yinbo. 2009. Microgrid technology based on clean energy power generation system Power System and Clean Eenergy. 25(1):40-43.

[6]Wang chengshan, Wang Shouxiang. 2008. Study on some key problems related to distributed generation systems.. Automation of Electric Power System 32(10): 1-5, 31 